\title{
MEASURING GREEN ROOF PERFORMANCE, A SOLUTION TO SUSTAINABLE URBAN DEVELOPMENT IN THE UAE
}

\author{
U.D' SOUZA \\ F-o-CUS: Focus on Construction Urbanism Sustainability, UAE.
}

\begin{abstract}
The urban environment in the UAE is classified as hot and humid. During the summer months, humidity is high when compared with the winter months. Solutions for sustainable development are of high priority in the region to meet the goals of the UAE Vision and meet notable recommendations at the World Future Energy Summit (WFES) held in the UAE, January 2013. In order to achieve a balanced environment, help mitigate climate change and demonstrate a means of achieving a temperature reduction as recommended by Conference of Parties (COP) 18 held in Qatar, November 2012, a study on measuring the performance of green roof to reduce climatic temperatures in the UAE has been undertaken in the urban Dubai Marina development. Plant and air exchanges have been measured using ENVI-met micro-climatic simulation software. From previous research findings, parameters such as Surface Albedo (SA), Mean Radiant Temperature (MRT) and Relative Humidity $(\mathrm{RH})$ were instrumental in measuring green roof performance and effectiveness towards sustainable development. This research explores the impact of green roof on sustainable development given two different periods of the year, the summer solstice, June 21 st and the winter solstice, December 21 st. A simulation conducted during the two periods on ENVI-met investigates the following parameters, SA, MRT, RH, Predicted Mean Vote (PMV) and Wind Speed. Evidence suggest gains in using green roofs to entice city authorities and relevant decision makers of the value added benefits of green roofs in sustainable urban development, to meet temperature reduction standards, mitigate heat islands and enhance the built environment.

Keywords: Green roofs, high density development and built environment, sustainable development, thermal performance, urban planning.
\end{abstract}

\section{INTRODUCTION}

The urban Dubai micro-climate is rapidly changing and population is predicted to increase by the year 2050. Discussions at the Conference of Parties (COP) 18 in Qatar addressed the need to determine ways of meeting carbon emission and temperature reduction targets. In 2008, the Dubai municipal government adopted a green building initiative to promote green roofs as a means of alleviating carbon emissions and reducing building energy consumption. As a strategic energy saving solution for sustainable development (meeting the needs of the present generation while considering the needs of future generations), green roofs can deflect long wave radiation and mitigate hot spots or urban heat islands (UHIs) in dense areas.

Due to the increasing pace of urban developments, several solutions in the larger scheme of thing have been proposed as a planning measure, among one is the use of green roofs. However, an increasing awareness to capitalize on land use benefits by using green roofs is detrimental simply because of the environmental and energy benefits involved. These benefits are inclusive of everything from biodiversity and wildlife promotion, to air pollution reduction, solar radiation absorption, by provision of reflective materials, creating attractive open spaces and capitalizing on land available. By largely assessing the various benefits to be accommodated by green roofs, this research can aim to engage the construction community, developers and stakeholders to consider this alternative as a solution to sustainable development. In the current study, the UAE micro-climate has been modelled by ENVI-met simulation software and a comparison of a green roof and base roof development has been considered. 


\section{CLIMATIC CONDITIONS IN THE UAE}

Initially an assessment of the micro-climatic conditions conducted in the UAE found that data derived from the National Centre of Meteorology and Seismology in the UAE (NCMS) [1] showed temperature ranges in the UAE during the humid summer months reached a high of $48^{\circ} \mathrm{C}\left(118.4^{\circ} \mathrm{F}\right)$ in the warm winter months dropping to a minimum of $14^{\circ} \mathrm{C}\left(50^{\circ} \mathrm{F}\right.$ and $\left.57.2^{\circ} \mathrm{F}\right)$ (see Fig. 1). It was found that humid south-eastern winds (sharqi) are predominant over the coastal region during the summer and north-westerly cool winds (shamal) in the UAE mature during the winter months. During summer, humidity reaches a high of over $90 \%$, whereas it falls to $50 \%-60 \%$ in the coastal areas during winter periods NCMS [1]. Regular occurrence of dew formation is found with minimal rainfall, which is found during the winter months, while thunder and dust storms are frequent over the summer months and can be supplemented by severe flash floods by the south-eastern mountains.

\section{MEASURING GREEN ROOF PERFORMANCE BY OBSERVATION}

Sustainable development in the UAE micro-climate can be achieved by using green roofs as a means of regulating outdoor temperatures in the UAE [2-5]. Previous research undertaken on the green roof topic in similar hot humid climates of North Africa, Florida, Singapore and Bangladesh involve experimentation by measuring parameters such as Surface Albedo (SA), Mean Radiant Temperature (MRT) and Relative Humidity (RH) to determine thermal performance contributions to sustainable city environments and is explained below.

SA was previously studied in various scenarios to establish the effects of solar reflectivity of green roofs. In most cities, albedo levels ranges from 0.10 to 0.20 . A study conducted on North African towns demonstrated a precedent for high SA ranging between 0.30 and 0.45 , largely due to excessive vegetation in those towns. Taha [6] developed a mesoscale simulation model in Los Angeles, USA to decipher SA ranges due to urban vegetation and found a $2^{\circ} \mathrm{C}$ temperature reduction. This reduction led to a $10 \%$ reduction in air conditioning consumption. Sailor [4] conducted a simulation experiment in Florida, USA and found that a higher albedo due to incorporation

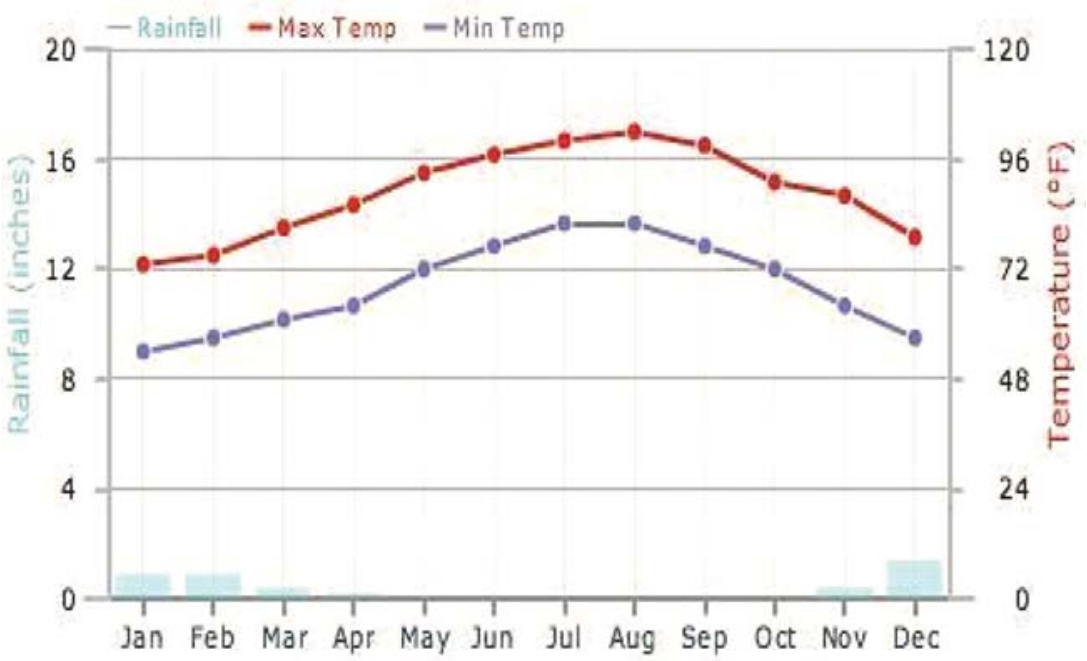

Figure 1: Dubai Weather (Dubai Information, 2011). 
of vegetation led to a $2^{\circ} \mathrm{C}$ temperature decrease similar to the study in LA. Eventually the aim of green roofs in sustainable urban development is to decrease temperature levels from $2^{\circ} \mathrm{C}$ to $4^{\circ} \mathrm{C}$. This can help mitigate UHI.

MRT determined when examining ambient air temperatures, global temperatures and air velocity mathematically formulated can be reduced by vegetated surfaces. A case study in Singapore by Wong et al. [7] discovered that long-wave radiation on hard surfaces could be controlled by the use on vegetation. It was deduced that the solar radiation exposure on hard surface emitted more long wave radiation when compared with those regulated by vegetation on roofs. Plants controlled thermal levels in an urban environment that can otherwise lead to discomfort depending on surface typology. MRT measured for vegetated roofs confirmed a reduced long-wave radiation emission regulated by plants and absorbed to the roof surface. An MRT study by Kakon and Nobou [8] on a modelled canyon in Dhaka, Bangladesh measured air flow movements in the surrounding environment. MRT levels varied depending on the type on urban environment, including vegetation, building typology, global temperatures, sky view factor (SVF) and building heights. The use of vegetation and air flow patterns can affect the humidity levels in sustainable development.

RH investigated by Wong et al. [9] found that there was no change in the RH between hard surfaces and vegetated surfaces. SVF can affect RH levels in some developments as noted by Kakon and Nobou [8] in Dhaka, Bangladesh. A higher SVF resulted in changes in RH levels in urban environments. RH increased due to higher air temperatures because of the amount of solar radiation absorbed. Other means of effecting RH in urban environments is through monitoring air flow patterns.

Identifiable knowledge gaps concluded from the above observation suggest that variations in simulated temperature profiles can validate the performance of green roof applications in sustainable development of cities. In Section 7, a case study on the thermal performance of green roofs can validate these knowledge gaps and contribute to the wider knowledge base community for green roofs have been reported.

\section{MEASURING TOOL FOR GREEN ROOF RESEARCH ENVI-met}

A micro-climatic numeric modelling software more commonly known as ENVI-met ${ }^{\circ}$ registered trademark (Nr. 30473 896) [10] developed by Michael Bruse can be utilized to assess the atmospheric conditions of the urban micro-climate by inputting the climate data collected. Software capabilities include using the fundamental laws of fluid and thermo-dynamics to simulate surface, vegetation and atmospheric interaction in the simulated micro-climate. Validity of ENVI-met has been scrutinized and utilized by scientific, government, academic and research institutions and although limitations [11-13] exist in the current version, interface and updates can be modified and programmed by relevant bodies. A documented analysis has been undertaken by Bruse [10] ensuring validation of scientific results through mathematical formulae.

\section{THE SELECTED UAE BUILT ENVIRONMENT}

As mentioned earlier, the green roof analysis took place in a dense urban development in Dubai, UAE. The emirate of Dubai is one among the seven emirates in the UAE (see Fig. 2) and located towards the north of country. The Dubai Marina Master Plan (see Fig. 3), a land area of approximately 578 Ha NRI [14] was developed by Emaar Properties PJSC and designed by architecture firm HOK. The city with city development model was conceptualized as a waterfront community housing luxury apartments, condominiums and villas. The high density community also serves offices, restaurants, retail and can be easily accessible as a walkable community because it serves as a pedestrian-friendly environment. 


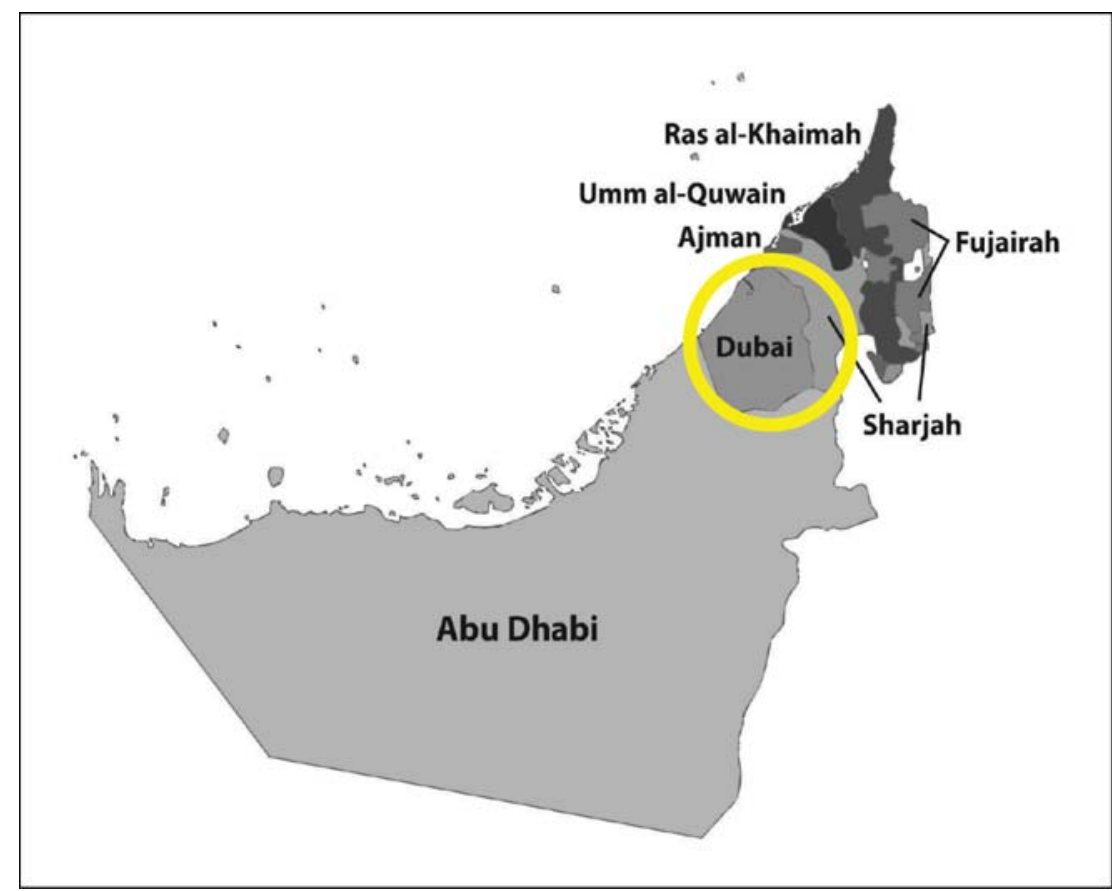

Figure 2: Location of Dubai (Berglee, 2012).

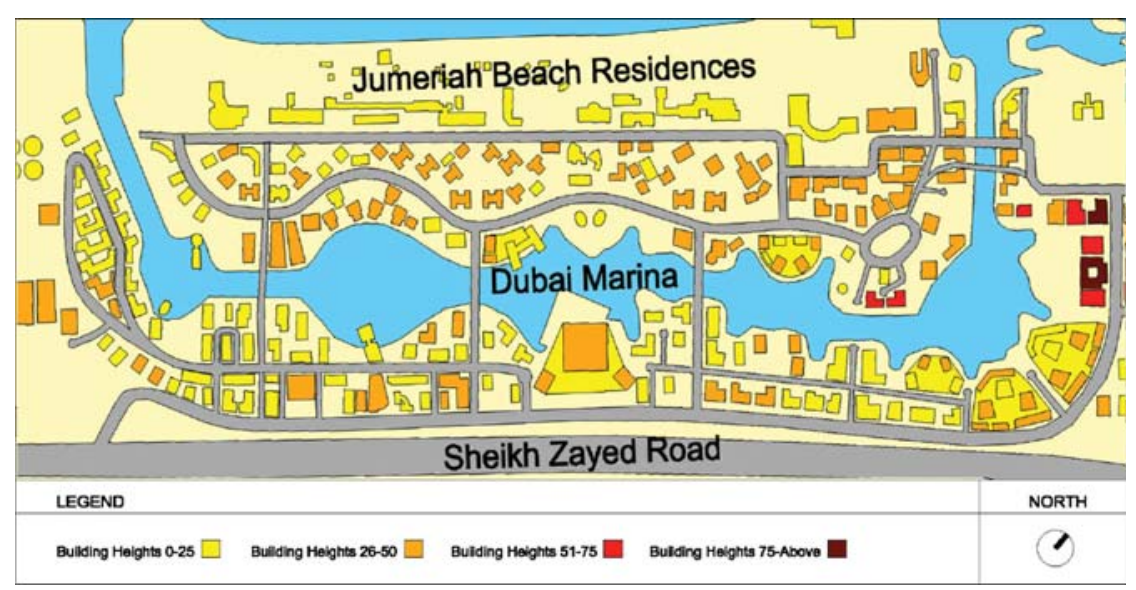

Figure 3: Site Area and Density Diagram.

\section{SIMULATING THE BUILT ENVIRONMENT WITH ENVI-met}

The chosen built environment was then simulated at June 21st, 2011, 1:00 pm and December 21st, 2011, 1:00 pm (see Fig. 4). ENVI-met measured the development context by means of fluid and thermodynamic calculations for surface/walls/roofs and plants [11], the process and means of the ENVI-met simulation is described in the following: 
- Simulation area inputs

Simulation area inputs represent the model size, location details, building information, dimensions and weather conditions. Plant inputs, soil and surface conditions are also included in the editor.

\section{- Simulation configuration}

The simulation configuration file utilizes the inputs documented and then prepares the simulation for model run. It involves ensuring that the performance parameters such as SA, temperature and RH are analysed.

\section{- Simulation run and outputs}

Simulation run and output test the simulation experiment based on the prescribed parameters, inputs and configurations. At 1:00 pm, the set parameters are tested on the dates of June 21st, 2011 and December 21st, 2011 due to environmental variations, sun angles and weather profile.

\section{- Simulation visualisation using LEONARDO}

After model run, the ENVI-met output then generated goes through the LEONARDO visualisation phase, which graphically represents the output file, time frame, area and measured values.

As mentioned earlier, the set simulation dates for the model run are June 21st, 2011 (summer solstice) and December 21st, 2011 (winter solstice). The summer solstice is when the sun is at the highest angle and also at peak intensity (see Fig. 4). Thermal performance levels are affected due to seasonal variations when the earth's surface does not encounter much solar gains from the sun in the northern hemisphere during the winter months compared with the intense summer months in the Middle East.

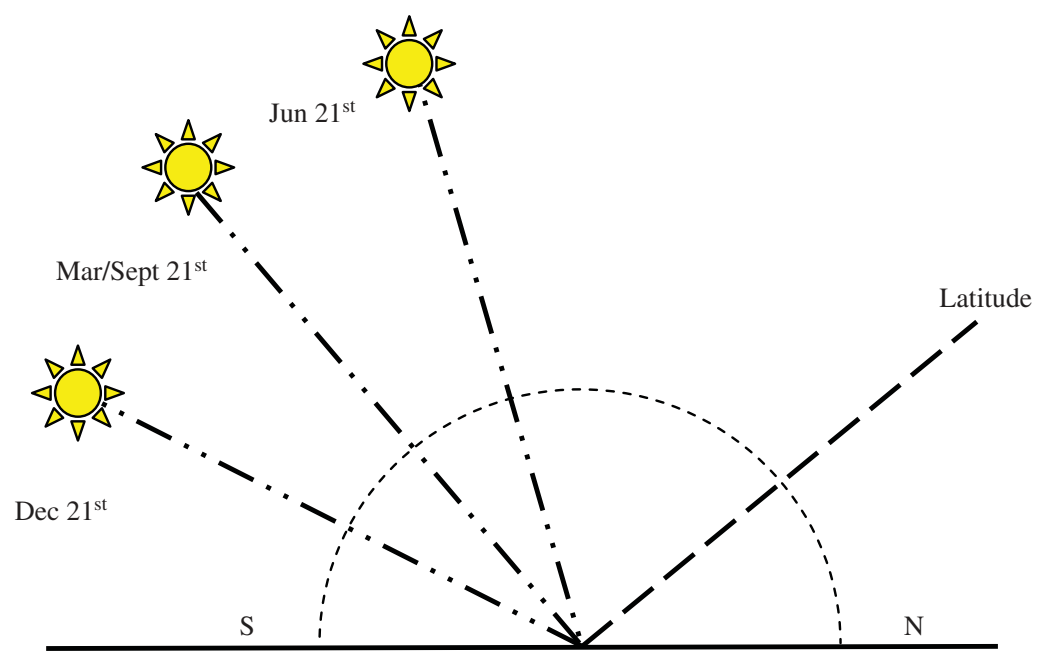

Figure 4: Sun Path Diagram.

\section{MEASURING GREEN ROOF PERFORMANCE BY SIMULATION AS A SOLUTION TO SUSTAINABLE DEVELOPMENT: RESULTS AND DISCUSSION}

In efforts to establish green roof as a solution to sustainable development in the UAE, a number of ENVI-met numeric simulation tests were conducted on a conventional roof case and a green roof case to define the thermal conditions for environmental advantage. Based on a selected section of the Dubai Marina the build environment was chosen with area and height as defined in Fig. 3. The developed ENVI-met model was based on the inputs discussed earlier for the dates of June 21st, 2011 and 
December 21st, 2011 while the scheduled time for simulation is at 1:00 pm on both dates. As this is a study of green roof performance, in depth details such as green roof typology (i.e. intensive, extensive, semi-intensive) has not been covered in this paper. However, plant and soil inputs were derived from the ENVI-met database based on the available selection. The following parameters have been studied, that is SA, MRT, RH, Predicted Mean Vote (PMV) and Wind Speed.

\subsection{Surface Albedo - Parameter 1}

The first parameter studied, SA, was evaluated on two different roof scenarios of the as-built models. SA, which measures the solar reflectivity of surface material, was conducted using ENVI-met to measure the difference in albedo levels during the summer period for the base and green roof scenario. The derived simulation run file was taken to LEONARDO to visualize the outputs. An increase in SA was found from the conventional model $0.12-0.16$ to $0.16-0.20$ in both summer and winter scenarios (see Fig. 5).

An increase in SA suggests that significant changes in input and area can yield increasingly advantageous results. These changes can be plant and material typology, green roof typology (intensive, semi-intensive and extensive) and area chosen, which if done on a large scale, can reduce surface temperature, control carbon emissions and reduce long-wave radiation emission.

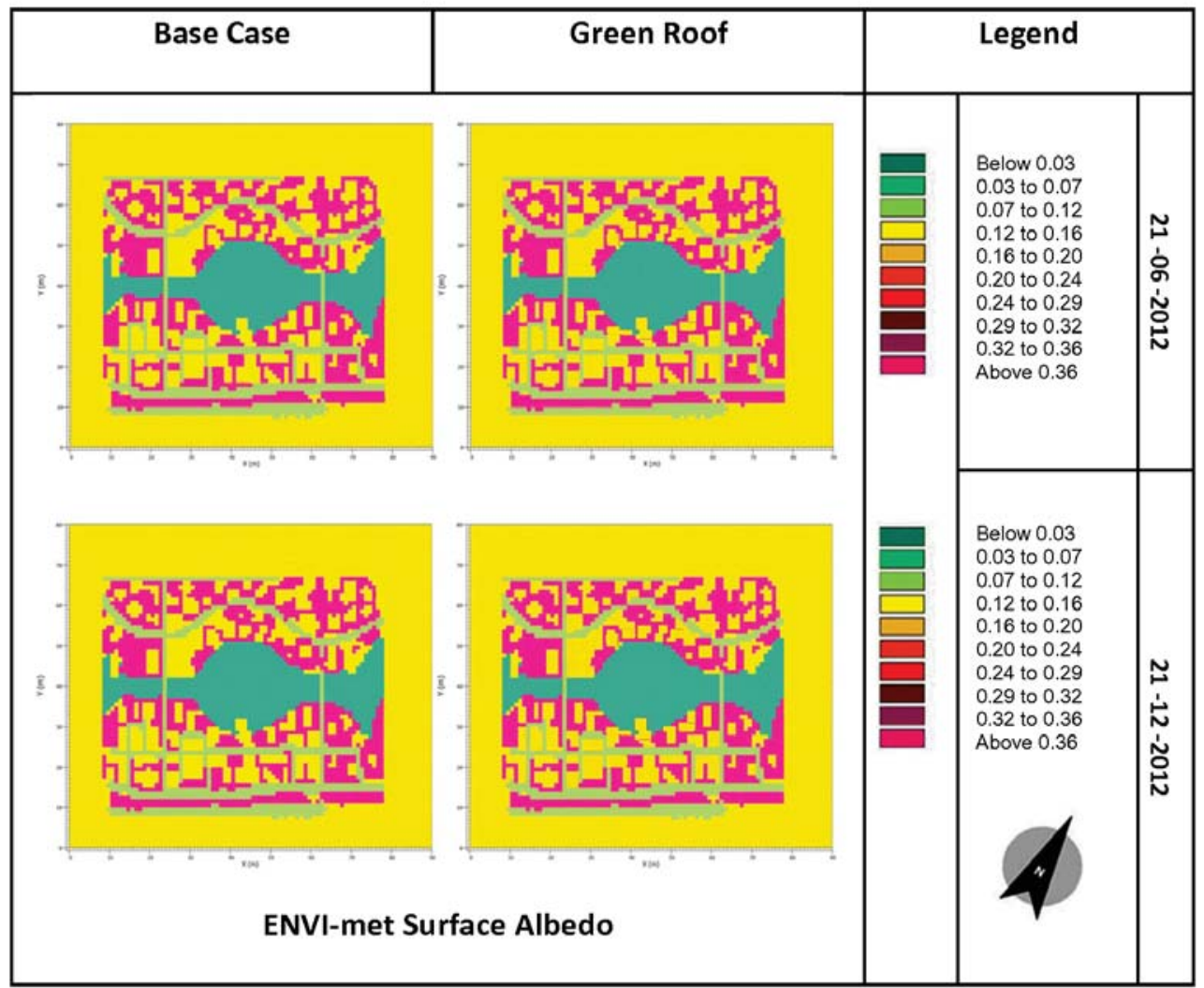

Figure 5: ENVI-met Surface Albedo (SA) results of base and green roof. 


\subsection{Mean Radiant Temperature - Parameter 2}

An ENVI-met analysis was conducted on Mean Radian Temperature (MRT) to measure the difference in levels during the summer period for the base and green roof scenario. Summer MRT documented in ENVI-met lies within the range of $49.62^{\circ} \mathrm{C}-51.73^{\circ} \mathrm{C}$ in the base roof and green roof scenario. Winter time MRT in contrast to summer time MRT was reduced and ENVI-met documented this result in the range of $36.91^{\circ} \mathrm{C}-39.03^{\circ} \mathrm{C}$ when compared with the summer time MRT from $49.62^{\circ} \mathrm{C}$ to $51.73^{\circ} \mathrm{C}$ (see Fig. 6).

Since there is a temperature change in MRT when compared with the base conventional green roof winter time roof scenario, it can be concluded that there are various factors that this change can be attributed to such as type of green roof installation, green roof design and surface type and plants used. Other factors include the fact that MRT can largely be affected by leaf foliage and density, which depending on type used, can be beneficial to the urban environment. In the current study, the selected plants typology and species used are a result of the available plants in the ENVI-met database (Fig. 6).

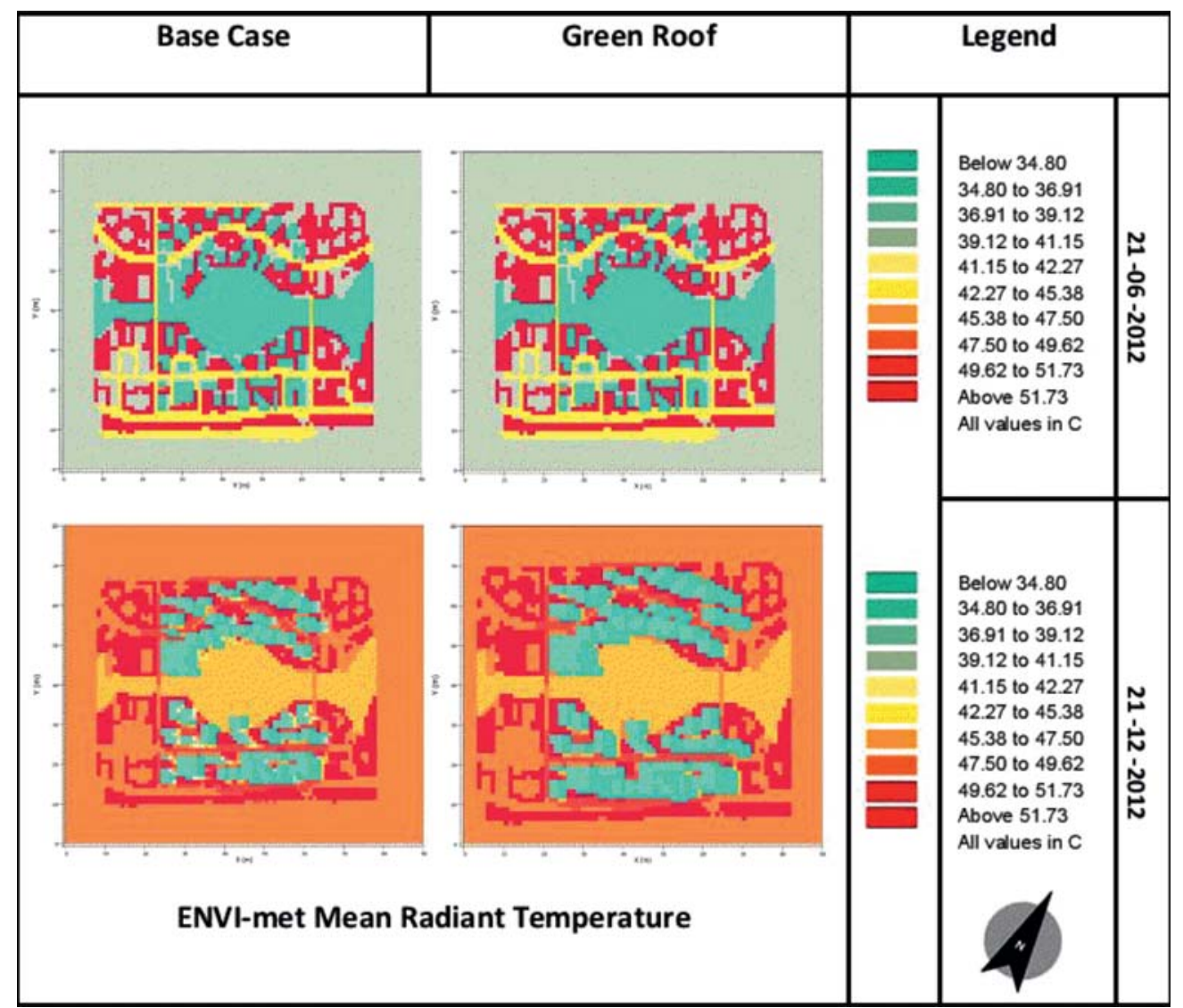

Figure 6: ENVI-met Mean Radiant Temperature (MRT) results of base and green roof. 


\subsection{Relative Humidity - Parameter 3}

Relative Humidity $(\mathrm{RH})$ was measured by ENVI-met in all four roof type scenarios of RH, which included summer time and winter time base case roof and green roof experiments. Once the model run was completed and the output visualized in LEONARDO, it was found that the summer time RH ranged from $83.44 \%$ to $86.87 \%$ for the conventional roof and green roof case typology, respectively (see Fig. 7).

During winter, RH levels reached above $108.05 \%$. RH on average in the dense urban context at 1:00 pm was found at $85 \%$. As a minor change in RH was found in between the summer and green roof base case scenario and green roof scenario from the ENVI-met simulation, further research is to be suggested on soil and substrate details and its impact on RH levels. The atmospheric interaction of soil, substrate and plant details can possibly yield better RH results. The external environment is also a contributing factor, simply because the development is located next to a man-made water feature and the sea. Therefore, the surrounding context and various weather conditions depending on periodic annual patterns can affect $\mathrm{RH}$ results.

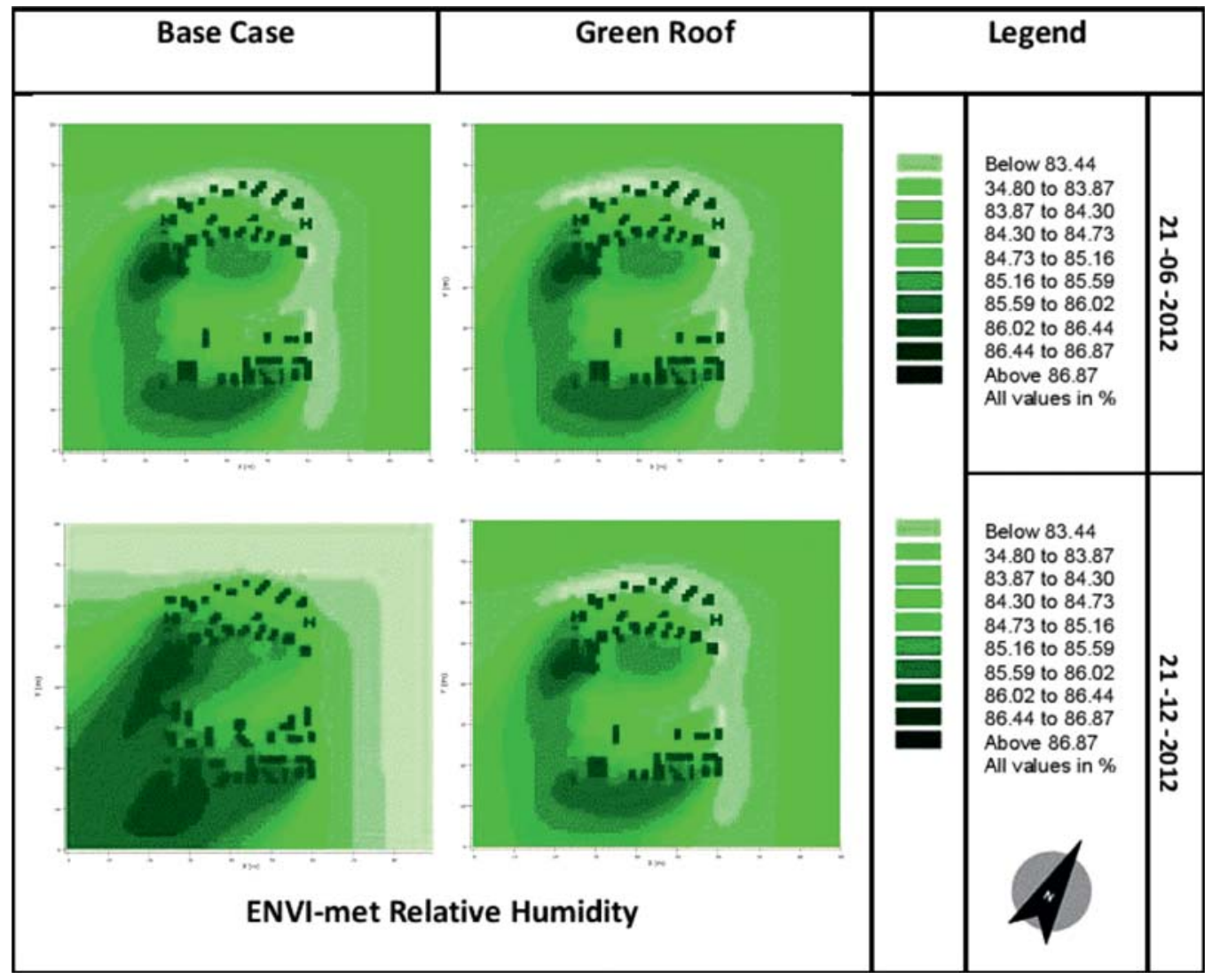

Figure 7: ENVI-met Relative Humidity $(\mathrm{RH})$ results of base and green roof. 


\subsection{Predicted Mean Vote - Parameter 4}

Predicted Mean Vote (PMV) measures the human thermal comfort levels evaluated by ENVI-met depicting a change in values from -0.51 to -0.35 in the base conventional roof to -0.01 to 0.33 in the green roof case modelled in summer. As this requirement meets the ANSI/ASHRAE Standard 55 $[14,15]$ and ISO $7730[16]$ range for thermal comfort of an individual $(-0.5$ to +0.5$)$. The slight change can be primarily due to minor levels of thermal sensations experienced by an individual on a small section of the Dubai Marina (refer to Section 5, Fig. 3). However, plant typology can be a defining factor in the experimentation process.

Subsequently, the green roof ENVI-met simulation measured during the winter period found PMV at -1.15 to -0.16 , it was noticeably different from the base case winter roof type scenario measured at -1.48 to -0.82 . In comparing the summer time green roof typology measured at 0.01 to 0.33 to the levels found in winter, it can be concluded that the winter time PMV levels is considerably cooler. The change in PMV, which is cooler in winter, can also be attributed to the north-westerly (shamal) winds (see Fig. 8). Wind temperatures sky view factors and surrounding context can affect the PMV results.

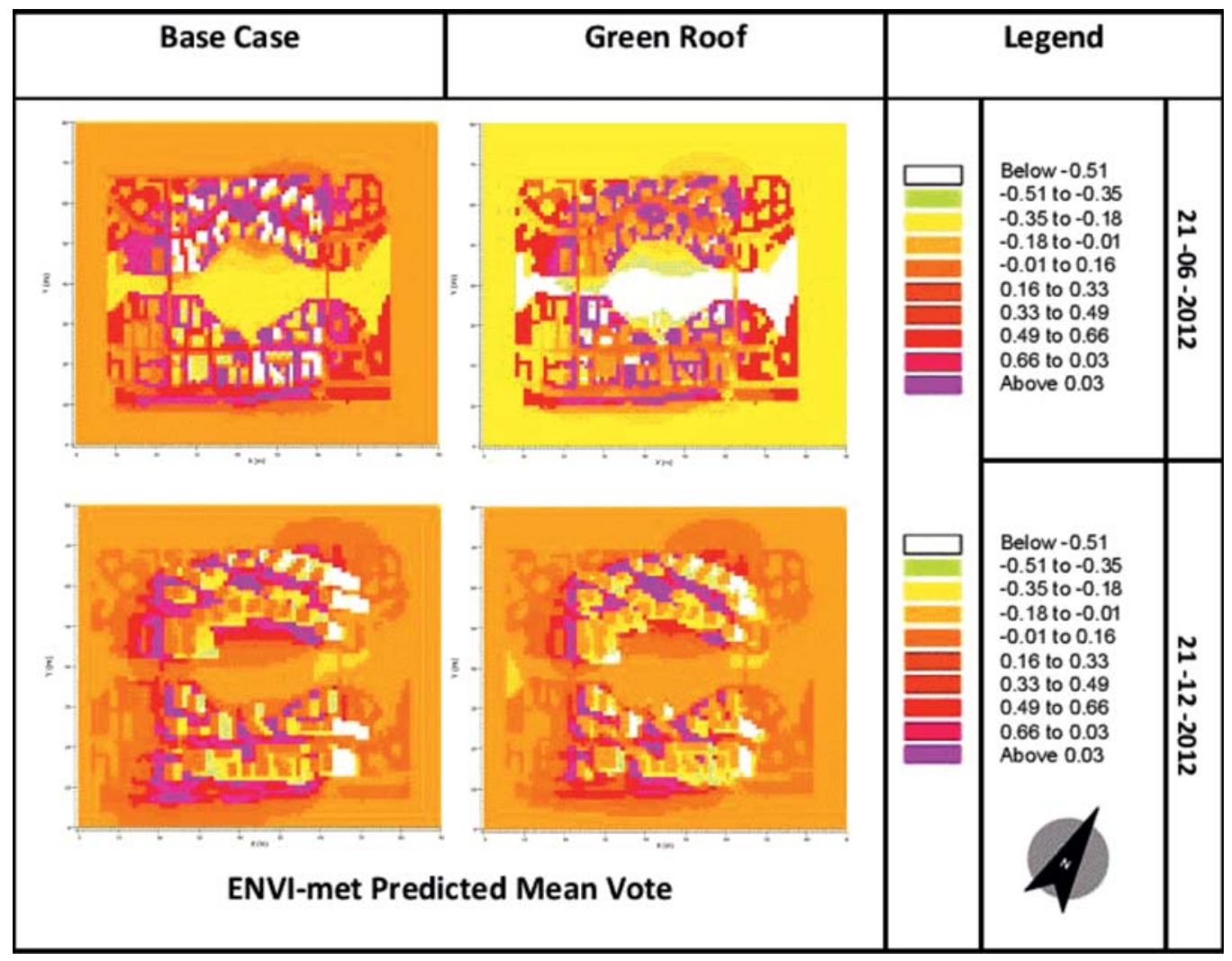

Figure 8: ENVI-met Predicted Mean Vote (PMV) results of base and green roof. 


\subsection{Wind Speed - Parameter 5}

Wind Speed among the parameter simulated on ENVI-met measured the difference in wind levels during summer and winter for the base and green roof scenario. As the ENVI-met simulation was run for all four models, the derived simulation file was visualized in the Leonardo program to define the expected outcomes. It was found that there was no change in the Wind Speed (see Fig. 9) outcomes during the summer time and winter time base case and green roof scenarios when simulated in the ENVI-met remained at a range of $0.47-1.68 \mathrm{~m} / \mathrm{s}$.

Although a low wind speed of $0.50-2.00 \mathrm{~m} / \mathrm{s}$ is deemed acceptable, other factors such as open areas, variation in building heights and plants (trees) can influence wind speed in the Dubai Marina development. Wind Speed was a relevant parameter chosen in the study simply because of the surrounding context its relation to the other parameters on the experimental ENVI-met simulation. It is recommended that further study on airflow patterns and high density building context can be relevant in understanding the process and possible influences in addressing the effectiveness of the thermal comfort of green roofs and its contribution to finding solutions to sustainable development in the UAE.

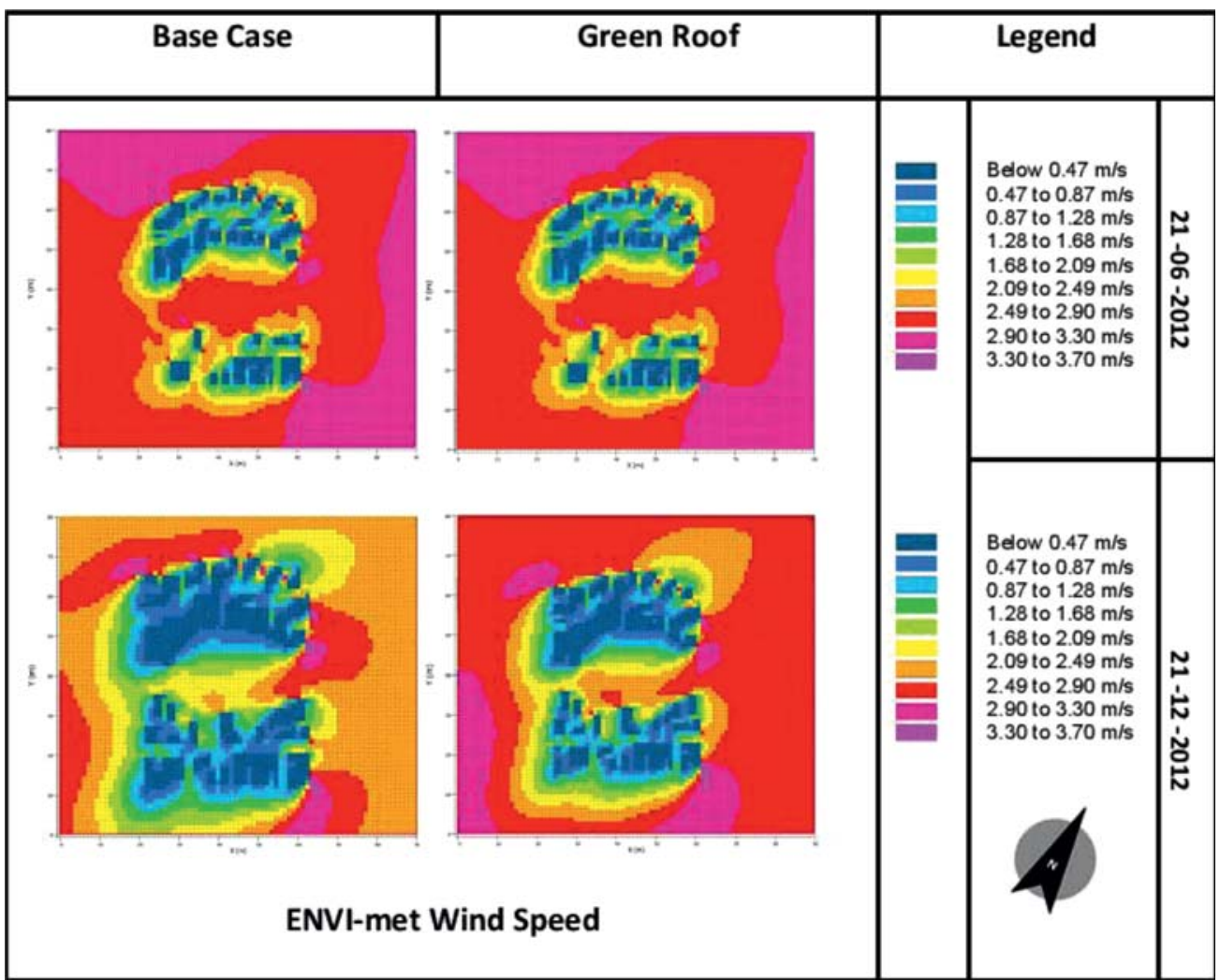

Figure 9: ENVI-met Wind Speed results of base and green roof. 
In evaluating all five parameters in the ENVI-met simulation, it was found that environmental factors such as MRT and RH were constant in all experimentation conducted and this can be because of the limited ENVI-met database inputs available for controlling the simulation environment. Again a variation in inputs available such as plants selection and foliage type can yield different results in the parameters studied. The types of green roofs available can also suggest changes in results. While green roofs protect the roof membrane from solar radiation absorption, MRT can be re-evaluated based on the ability for green roofs to prevent long wave radiation emitted and moderate the heat transfer co-efficient. In serving as a protection to incoming long wave radiation, green roofs can also insulate buildings via the roof, in effect reducing internal cooling loads and regulating energy consumption internally and mitigating UHIs externally. PMV levels deduced showed improved thermal comfort levels when paralleled to the base roof. These differences satisfied the ANSI/ASHRAE Standard $55[15,16]$ and ISO $7730[17]$ ranges for thermal comfort.

\section{CONCLUSIONS}

In conclusion, finding a solution to sustainable urban development in the UAE by measuring green roof performance has derived results to suggest that the implications of using green roofs can be critical to relevant stakeholders, governments, developers, architects and engineers. The main aim of this study was introduced by explaining how previous observation and measures were evaluated in assessing green roofs. An ENVI-met micro-climatic simulation model was run on a controlled site in the Dubai Marina given chosen dates and a chosen time frame. The following conclusions were derived from the results and compared with previous research undertaken.

SA has increased by adding plants to roofs in the Dubai Marina development. Previous research investigated by Taha [6] and Sailor [4] found that vegetation indefinitely resulted in higher albedos. Depending on area chosen, green roof typology and plants selected, a further increase in SA can be achieved, which can result in a city wide temperature decrease if used on a large scale as concluded by the ENVI-met simulation conducted.

MRT has reduced with the implementation of the vegetated roof on the Dubai Marina context. Using vegetation can control the effects of long wave radiation on the roof surface when compared with a conventional roof. Similar findings by Wong et al. [7] and Kakon and Nobou [8] indicated that vegetation on roof can benefit MRT. This was further confirmed by the ENVI-met simulation on the Dubai Marina by assessing the difference in MRT between the summer and winter months.

RH levels decreased in the summer when compared with the RH levels in winter as concluded in the ENVI-met simulation. It was assessed that this change in temperature could possibly be because of the shamal winds in the winter. High wind temperatures and its effect on RH was parallel to the finding of Wong et al. [9] and Kakon and Nobou [8], which concluded that air movements and building heights impacted RH. In the Dubai Marina ENVI-met simulation, little change was found between the conventional roof and green roof in summer and winter. This finding could be due to the proficient disparity of building heights in the Dubai Marina regulating air flow.

The PMV measuring human thermal comfort via ENVI-met simulation during winter of the green roof was found to be at -0.51 to -0.35 when compared with the conventional roof range of -0.01 to 0.33 . In contrast, the summer time green roof measured at -1.15 to -0.16 from convention roof at -1.48 to -0.82 in summer. Evidence from ANSI/ASHRAE Standard $55[15,16]$ and ISO 7730 [17] of human thermal comfort for PMV levels is between -0.5 and +0.5 . The ENVI-met simulation of the Dubai Marina concluded that the green roofs did indeed create a cooler environment and these changes were more prominent in winter. 
Wind Speed remained the same in all four ENVI-met models of green roof and conventional roof during summer and winter. As researched by Wong et al. [9] and Kakon and Nobou [8], wind speed was influenced by building height, width and orientation. Further investigation on air flow patterns and plant typology can decipher more details on the impact of green roofs and wind.

Lastly, the above parameters measured by ENVI-met indicate that green roofs can be a recommended solution to sustainable urban development. Sustainable development is a priority in this region as acknowledged by the Vision for the UAE and due to notable recommendations for sustainable development as indicated by the World Future Energy Summit (WFES) held in the UAE, January 2013 and discussed at the COP 18 held in Qatar, November 2012. ENVI-met is marginalized by software constraints such as a limited plant and substrate database, which if enhanced, can impact the five parameters evaluated in this research. As a specialized numeric modelling software, ENVI-met effectively measures the performance of the five parameters, SA, MRT, RH, PMV and Wind Speed. As a conceptual tool, ENVI-met demonstrated the impacts of using green roof as a solution to sustainable development by graphically representing the potential benefits. From ENVImet it was possible to realize the feasible outcomes of the performance measures, for instance the increase in SA to indicate the potential for temperature reduction and the improved PMV outdoor human thermal comfort levels by using green roofs. Environmental circumstance and sustainable urban planning practices undertaken in the ENVI-met simulation support the aim of this research, which is to advance green roof development. Essential monitoring of large scale developments, building variations and densities based on observed government policies, available green roof technical systems and typology will additionally need to be observed. Quantitative results can then be inferred from standardized parameters to suit preceding studies on the topic while, conclusive research findings can be recommended for future research. Deciphering the similarities and differences of possible outcomes can then supplement a precise technical objective based on the quality of green roof performance measured and systematic components. Ultimately, this can then efficaciously communicate the performance of green roofs as a viable and necessary solution for sustainable urban development and construction in the UAE.

\section{ACKNOWLEDGEMENT}

Dr Hanan Taleb, Faculty of Engineering and IT at The British University in Dubai, UAE and Welsh School of Architecture, Cardiff University, UK.

\section{REFERENCES}

[1] National Centre of Meteorology and Seismology in the UAE. [Online] http://www.ncms.ae/ english/, 2010.

[2] Dubai Municipality, Green Roof Manual: Guidelines for Planning, Execution \& Maintenance of Green Roof Various Applications. Dubai Municipality, Government of Dubai, UAE. [Online] pp. 1-46, www.dm.gov.ae, 2009.

[3] Dubai Municipality, Dubai Green Building Regulations. Dubai Municipality, Government of Dubai, UAE. [Online] pp. 1-46, www.dm.gov.ae, 2010.

[4] Sailor, D.J., A green roof model for building energy simulation programs. Energy and Buildings, 40(8), pp. 1466-1478, 2008.

[5] Shashua-Bar, L. \& Hoffman, M., Quantitative evaluation of passive cooling of the UCL microclimate in hot regions in summer, case study: urban streets and courtyards with tress. Building and Environment, 39(9), pp. 1087-1099, 2004.

[6] Taha, H., Urban climates and heat islands: albedo, evapotranspiration, and anthropogenic heat. Energy and Buildings, Oxford, 25(2), pp. 99-103, 1997. 
[7] Wong, N., Cheong, D., Yan, H., Soh, J., Ong, C., \& Sia, A., The effects of rooftop garden on energy consumption of a commercial building in Singapore. Energy and Buildings, 35(4), pp. 353-364, 2003b.

[8] Kakon, A.N., \& Nobuo, M., The sky view factor effect on the microclimate of a city environment: a case study of Dhaka City. Proceedings of the 7th International Conference on Urban Climate, June 29 - July 3, Yokohama, Japan, pp. 1-4, 2009.

[9] Wong, N., Chena, Y., Ong, C. \& Siab, A., Investigation of thermal benefits of rooftop garden in the tropical environment. Buildings and Environment, 38(1), pp. 261-270, $2003 \mathrm{a}$.

[10] Bruse, M., ENVI-met registered trademark (Nr. 30473 896) [Online] http://www.envimet. com, 2003.

[11] Bruse, M., Modelling and Strategies for Improved Urban Climates. [Online] http://www. envi-met.com/documents/papers/strategies1999pdf, 1999.

[12] Okeil, A., A holistic approach to energy efficient building forms. Energy and Buildings, 42(9), pp. 1437-1444, 2010.

[13] UAEInteract, UN Conference on Trade and Development (UNCTAD). [Online] www.uaeinteract. com/docs/UAE_population, 2010.

[14] NRI, Dubai Marina, Dubai, U.A.E. [Online] Net Resources International. http://www. designbuild-network.com/projects/dubai-marina/, 2011.

[15] American Society of Heating Refrigerating and Air Conditioning Engineers (ASHRAE). Thermal Environmental Conditions for Human Occupancy. (ASHRAE Standard 55-1992). Atlanta, GA, 1992.

[16] American Society of Heating Refrigerating and Air Conditioning Engineers (ASHRAE). Thermal Comfort. ASHRAE Handbook: Fundamentals (pp. 8.1-8.29). Atlanta, GA, 2001.

[17] ISO Standard 7730, Moderate thermal environments determination of the PMV and PPD indices and specifications of the conditions for thermal comfort. International Standards Organizations, pp. 1-26, 1994. 